\title{
High Mobility Group Box 1 Induces a Negative Inotropic Effect on the Left Ventricle in an Isolated Rat Heart Model of Septic Shock
}

\author{
A Pilot Study
}

Satoshi Hagiwara, MD; Hideo Iwasaka, MD;

Tomoko Uchino, MD; Takayuki Noguchi, MD

\begin{abstract}
Background Sepsis can be exacerbated by an inappropriate immune response and the severe impact of this disease on the cardiovascular system is well documented. High mobility group box 1 (HMGB1) protein is an important mediator in the pathogenesis of sepsis and its role in cardiovascular system dysfunction was investigated in an lipopolysaccharide (LPS)-induced rat model of sepsis.

Methods and Results Twelve hours after intravenous bolus injections of LPS (5 mg/kg), rats were killed and heart samples were harvested. Immunoblot analysis was performed to assess expression levels of HMGB1 in cardiac myocytes. Left ventricular developed pressure (LVDP) served as a measure of systolic function. LPS administration was associated with an increase in the expression of HMGB1 in cardiac myocytes and a decrease in cardiac function. Hearts from the LPS-treated rats were also perfused with recombinant HMGB1 and cardiac function measured. The dose-dependent effects observed with elevated HMGB1 included decreased LVDP, decreased left ventricular $(\mathrm{LV})+\mathrm{dP} / \mathrm{dtmax}$, decreased absolute value of LV-dP/dtmin, and increased LV end-diastolic pressure.

Conclusions HMGB1 stimulation produces a negative inotropic effect during septic shock, suggesting an important role for this molecule in cardiovascular system dysfunction during sepsis. (Circ J 2008; 72: 1012-1017)
\end{abstract}

Key Words: Cardiac function; HMGB1; Negative inotropic; Sepsis

$\mathbf{M}$ ortality associated with septic shock is thought to be a consequence of severe derangements in the cardiovascular system, with myocardial dysfunction playing a primary role? Indeed, reduced cardiac contractile function has been observed both in septic patients $\mathrm{s}^{3,4}$ and experimental animal models of lipopolysaccharide (LPS)-induced sepsis? The cellular and molecular mechanisms responsible for these effects, however, remain incompletely understood.

Recent studies in rat and mouse models of sepsis have partially elucidated these mechanisms. One key factor that has emerged is high mobility group box 1 (HMGB1) protein, which serves as a late-phase mediator in the pathogenesis of sepsis. HMGB1 is an intranuclear protein that was originally identified as an important gene regulator6 Following the activation of the inflammation cascade, HMGB1 is released from necrotic damaged cells and secreted by activated monocytes and macrophages. Its mechanism of action is presumably via its affinity for receptors for advanced glycation end-products, Toll-like receptor 2 and Toll-like

(Received November 26, 2007; revised manuscript received January 27, 2008; accepted January 30, 2008)

Department of Brain and Nerve Science, Anesthesiology, Oita University Faculty of Medicine, Yufu, Japan

Mailing address: Satoshi Hagiwara, MD, Department of Brain and Nerve Science, Anesthesiology, Oita University Faculty of Medicine, 1-1 Idaigaoka, Hasama-machi, Yufu 879-5593, Japan. E-mail: saku@ med.oita-u.ac.jp

All rights are reserved to the Japanese Circulation Society. For permissions, please e-mail: cj@j-circ.or.jp receptor 4. HMGB1 binding to its receptors activates intracellular signaling pathways, such as the NF-kB pathway, which induce downstream cytokine release? thereby enhancing the inflammatory response, 89

LPS, a cell membrane component shed from Gramnegative bacteria, is a key mediator of septicemia and its pathogenic effects on the heart ${ }^{10}$ but exactly how this endotoxin causes cardiac dysfunction remains largely unclear. We hypothesized that HMGB1 might be a key mediator in the pathogenesis of cardiac dysfunction and to test this, we exposed hearts from LPS-treated rats to recombinant HMGB1 protein.

\section{Methods}

Materials

Recombinant HMGB1 was purchased from Shino-Test Corporation (Tokyo, Japan) and LPS (O127:B8) was obtained from Sigma (St Louis, MO, USA). All reagents were of the highest available analytical grade.

\section{Animals}

Male Wistar rats weighing 250-300g (Kyudou, Saga, Japan) were used in all experiments. All rats received humane care in compliance with the National Institute of Health (NIH) guidelines and the Principles of Laboratory Animal Care. All animals were housed with free access to food and water. 

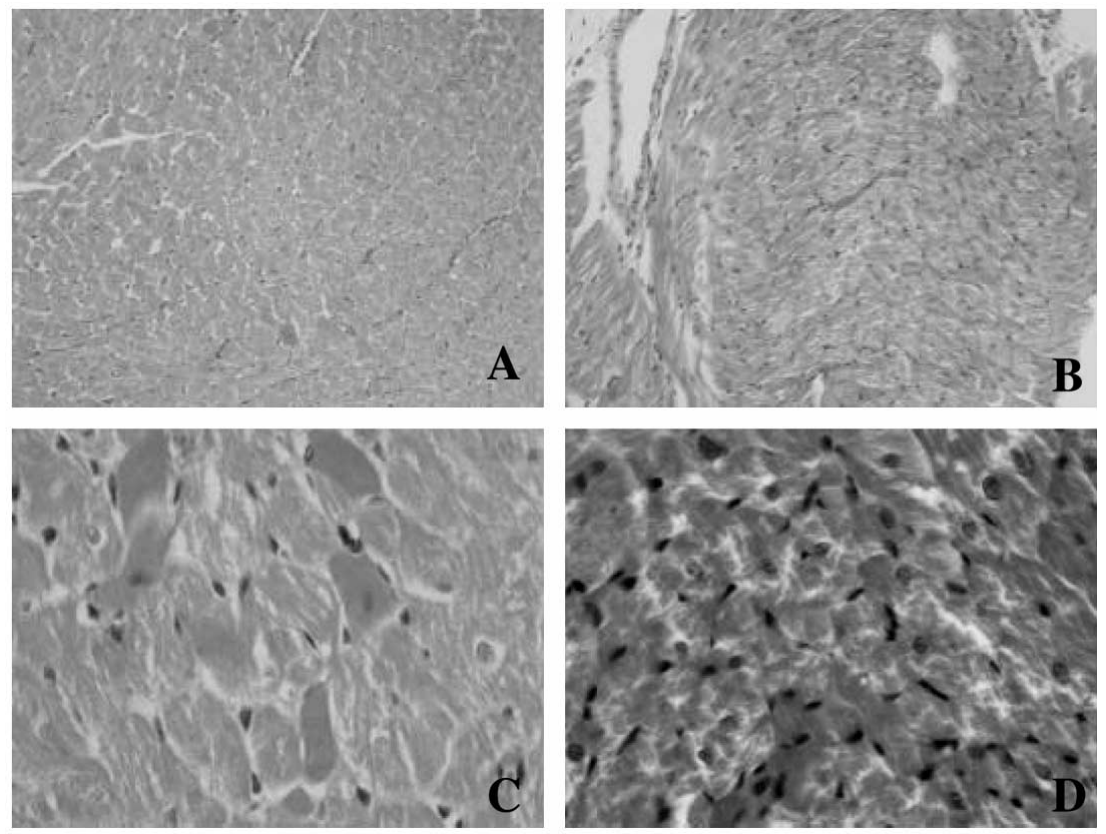

Fig 1. Effects of lipopolysaccharide (LPS) treatment on the gross histopathology of cardiac tissue. At $12 \mathrm{~h}$ after LPS injection, cardiac tissue from the control $(\mathrm{A}: \times 100, \mathrm{C}: \times 400$; $\mathrm{H} \& \mathrm{E})$ and LPS groups $(\mathrm{B}: \times 100, \mathrm{D}: \times 400$; $\mathrm{H} \& \mathrm{E})$ was analyzed and no gross changes were found in either group.

\section{Experimental Protocols}

The rats were randomly assigned to 1 of 2 treatment groups. The 6 animals in the control group received an intravenous bolus injection of $0.9 \% \mathrm{NaCl}$ solution alone. The 6 animals in the LPS group received an intravenous bolus injection of LPS dissolved in $0.9 \% \mathrm{NaCl}$ solution $(5 \mathrm{mg} / \mathrm{kg}))^{11}$ All rats were killed under general 2\% sevofluren anesthesia $12 \mathrm{~h}$ following injection. Tissue specimens were immediately removed surgically and processed.

\section{Histological Analysis}

Heart tissue specimens were instilled with $10 \%$ formalin. The samples were embedded in paraffin and cut into $4 \mu \mathrm{m}$ sections for staining with hematoxylin and eosin.

\section{Immunoblotting Analysis}

The hearts were harvested from all animals. After the blood was washed out using saline perfusion, the heart was homogenized with a T-PER (Tissue Protein Extraction Reagent: Pierce, Rockford, IL, USA) in a polytron homogenator (IKA Labortechnik, Staufen, Germany). The homogenates were then centrifuged at $10,000 \mathrm{~g}$ for $5 \mathrm{~min}$ at $4^{\circ} \mathrm{C}$. The concentration of protein in the collected supernatant was measured by absorbance at $562 \mathrm{~nm}$ using the BCA Protein Assay Regent system (Pierce).

For gel electrophoresis, equal quantities of protein (100 $\mathrm{g}$ ) were suspended in sodium dodecyl sulfate (SDS)-polyacrylamide gel electrophoresis (PAGE) buffer. Protein samples were boiled for $1 \mathrm{~min}$ and separated using a 10\% SDSpolyacrylamide gel. Protein runs using SDS-PAGE were immediately electrotransferred to polyvinylidene difluoride membrane (PVDF) (Millipore, Bedford, MA, USA) at $60 \mathrm{~V}$ for $3 \mathrm{~h}$ in a wet transfer system containing $20 \mathrm{mmol} / \mathrm{L}$ Tris$\mathrm{HCl} / 0.2 \mathrm{~mol} / \mathrm{L}$ glycine in $20 \%$ methanol as the transfer buffer. The membrane was blocked with 5\% nonfat dry milk in Tris/Tween buffer [ $25 \mathrm{mmol} / \mathrm{L}$ Tris-HCl; $2 \%$ Tween 20 (Bio-Rad Lab, Hercules, CA, USA); $0.14 \mathrm{~mol} / \mathrm{L} \mathrm{NaCl}]$ overnight at $4^{\circ} \mathrm{C}$.

Antibodies to HMGB1 (Shino-Test Corporation) or $\beta$ actin (Abcam, Cambridge, UK) were used as the primary antibody. The immune serum was diluted 500-fold with $1 \%$ nonfat dry milk and incubated with gentle shaking for $1 \mathrm{~h}$. The PVDF membrane was then rinsed 3 times with TBS/ Tween buffer for $10 \mathrm{~min}$. The secondary antibody was diluted 1,000-fold with $1 \%$ nonfat dry milk and incubated with the membrane for $1 \mathrm{~h}$. The blot was then washed by rinsing with TBS/Tween 3 times for $10 \mathrm{~min}$. The membrane was treated with enhanced chemiluminescence reagent (Amersham, Buckinghamshire, UK) and then exposed to X-ray film. After scanning the X-ray film, the band concentration was calculated by quantification of the integrated optical density using NIH Image J software package (NIH, Bethesda, MD, USA).

\section{Measurement of HMGB1 Secretion}

Serum samples were assayed using the ELISA sandwich method and 96-well plates that were precoated with monoclonal antibodies specific to rat HMGB1 (Shino-Test Corporation). The samples, negative controls, and diluted HMGB1 standard markers were added to each well. Detection of HMGB1 in the samples was performed according to the manufacturer's protocols. The A450 values were determined using an ELISA reader.

\section{Isolated Heart Perfusion and Assessment of Cardiac Function}

Cardiac function was determined by a modified isovolumetric Langendorff technique as described elsewhere ${ }^{12-14}$ and expressed as left ventricular developed pressure (LVDP), left ventricular end-diastolic pressure (LVEDP), left ventricular $(\mathrm{LV})+\mathrm{dP} / \mathrm{dtmax}$, and $\mathrm{LV}-\mathrm{dP} / \mathrm{dtmax}$. At the termination of the experiments, beating hearts were rapidly excised into oxygenated Krebs-Henseleit solution containing $11 \mathrm{mmol} / \mathrm{L}$ glucose, $2.0 \mathrm{mmol} / \mathrm{L} \mathrm{CaCl}, 4.3 \mathrm{mmol} / \mathrm{L}$ $\mathrm{KCl}, 25 \mathrm{mmol} / \mathrm{L} \mathrm{NaHCO} 3,118 \mathrm{mmol} / \mathrm{L} \mathrm{NaCl}, 1.2 \mathrm{mmol} / \mathrm{L}$ $\mathrm{MgSO}_{4}$, and $1.2 \mathrm{mmol} / \mathrm{L} \mathrm{KH}_{2} \mathrm{PO}_{4}$. Normothermic retrograde perfusion was performed with this solution in an isovolumetric and nonrecirculating mode. The perfusion buffer was saturated with a gas mixture of $95 \% \mathrm{O}_{2}-5 \% \mathrm{CO}_{2}$ at a $\mathrm{pH}$ of 7.4. Perfusion pressure was maintained at $75 \mathrm{mmHg}$. 
A

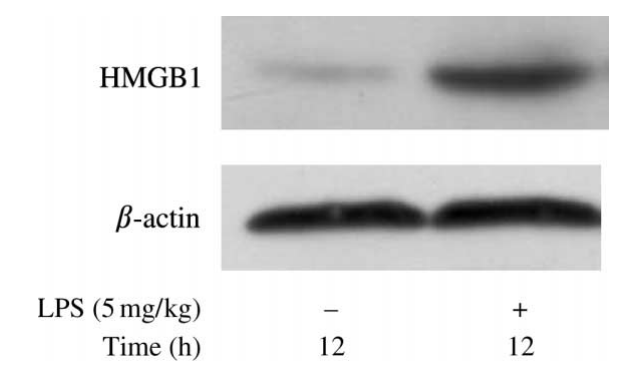

B

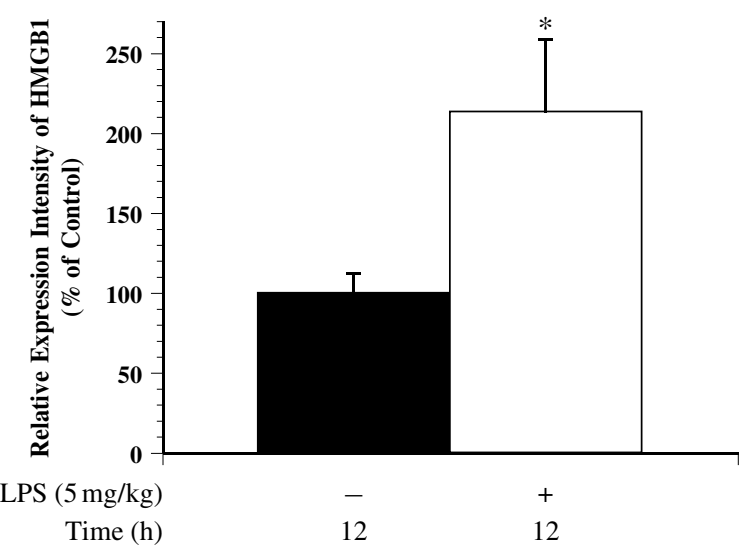

Fig 2. Effects of LPS treatment on high mobility group box 1 (HMGB1) expression in cardiac tissue. (A) Immunoblots showing HMGB 1 and $\beta$-actin protein expression in the heart tissue from a representative control or LPS animal. (B) Signal intensities for the density of HMGB1 protein immunoblot bands ( $n=4$ for each group). HMGB1 protein levels were quantified using an image analyzer and normalized to $\beta$-actin levels. Combined expression intensities of HMGB1 are shown as percentages of the control. Data are mean \pm standard error of the mean (SEM). $* \mathrm{p}<0.05$ relative to the control group. See Fig 1 for other abbreviation.

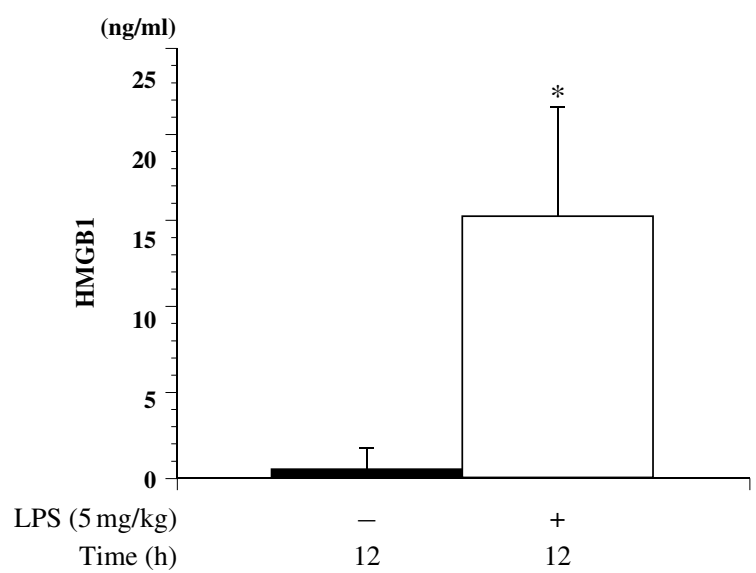

Fig 3. Differences in HMGB1 serum concentration between control (white bar; $n=6$ ) and LPS rats (black; $n=6$ ). All data are mean \pm SEM. An asterisk denotes a difference vs administration of LPS ( $<<0.05)$. See Figs 1,2 for abbreviations.

A latex balloon was inserted through the left atrium into the left ventricle, and filled with water $(0.18-0.28 \mathrm{ml})$. LVDP, LVEDP, $+\mathrm{dP} / \mathrm{dtmax}$, and $-\mathrm{dP} / \mathrm{dtmax}$ were continuously recorded with a computerized pressure amplifier-digitizer (BIOPAC Systems, Inc, Goleta, CA, USA). After $20 \mathrm{~min}$ of perfusion (to reach equilibrium), the inotropic effects were measured in the presence of varying concentrations of recombinant HMGB1 added to the perfusion solution. Myocardial temperature was maintained at $37^{\circ} \mathrm{C}$ through the circulation of warm water.

\section{Statistical Analysis}

All descriptive data are presented as the means \pm standard error of the mean. The data were analyzed by repeated measurement ANOVA for multiple comparisons, and by unpaired t-test for single comparisons. A p-value $<0.05$ was considered to be statistically significant.

\section{Results}

\section{Cardiac Tissue Pathology}

We investigated whether LPS-induced sepsis would affect cardiac histopathology. No histological alterations were observed, however, in either the control or the LPStreated group (Figs 1A-D).

\section{HMGB1 Expression in Cardiac Tissue and Serum}

We next examined whether LPS treatment would affect the levels of HMGB1 in cardiac tissue and serum. At $12 \mathrm{~h}$ after LPS treatment, heart tissue was isolated and analyzed by immunoblotting. Levels of HMGB1 protein in tissue from LPS-treated animals were at least 2-fold higher than those in the control group (Figs 2A,B). Prior to LPS administration, HMGB1 was barely detectable in the sera of rats from either group. Following LPS injection, HMGB1 levels increased markedly, so that by $12 \mathrm{~h}$ post-injection the expression was higher than in the control group (Fig 3).

\section{Isolated Heart Perfusion and General Effects of LPS Treatment}

Heart rate (HR) did not differ between the control and LPS groups (Fig 4A), but LPS group animals demonstrated a higher LVEDP at $12 \mathrm{~h}$ after exposure to LPS compared with the control groups (Fig 4B). As shown in Fig 4C, hearts subjected to LPS exhibited a significant impairment of LVDP. $\mathrm{LV}+\mathrm{dP} / \mathrm{dtmax}$, the rate of pressure rise during contraction (Fig 4D), was lower in the LPS group than in the control group $(\mathrm{p}<0.05) . \mathrm{LV}-\mathrm{dP} / \mathrm{dtmin}$, the maximum rate of relaxation (Fig 4E), was also lower in the LPS group $(\mathrm{p}<0.05)$. Twelve hours after exposure to LPS, the isolated hearts demonstrated significantly lower LVDPs.

\section{Effect of HMGB1 on Myocardial Function \\ in Control Animals}

Perfusion with $0.1 \mu \mathrm{g} / \mathrm{ml}$ HMGB1 had no apparent effect on HR, LVEDP, LVDP, LV+dP/dtmax, or LV-dP/dtmin (data not shown). We then investigated the effect of 1 and $10 \mu \mathrm{g} / \mathrm{ml}$ HMGB1 on cardiac performance in the control animals. Perfusion with $10 \mu \mathrm{g} / \mathrm{ml} \mathrm{HMGB} 1$ had no effect on HR (Fig 4A), LVEDP (Fig 4B) or LV-dP/dtmin (Fig 4E). It did, however lead to small decreases in LVDP (Fig 4C) and $\mathrm{LV}+\mathrm{dP} / \mathrm{dtmax}(\mathrm{Fig} 4 \mathrm{D})$, although these changes were not significantly different.

\section{Effect of Combined LPS Treatment With HMGBI on Myocardial Function}

After LPS treatment, hearts were removed and perfused with HMGB1 for a period of 10 min and cardiac function was measured. Perfusion with 1 or $10 \mu \mathrm{g} / \mathrm{ml}$ HMGB1 resulted in no changes in HR (Fig 4A). Perfusion of $0.1 \mu \mathrm{g} / \mathrm{ml}$ HMGB1 had no effect on HR, LVDP, LVEDP, LV+dP/ 
A

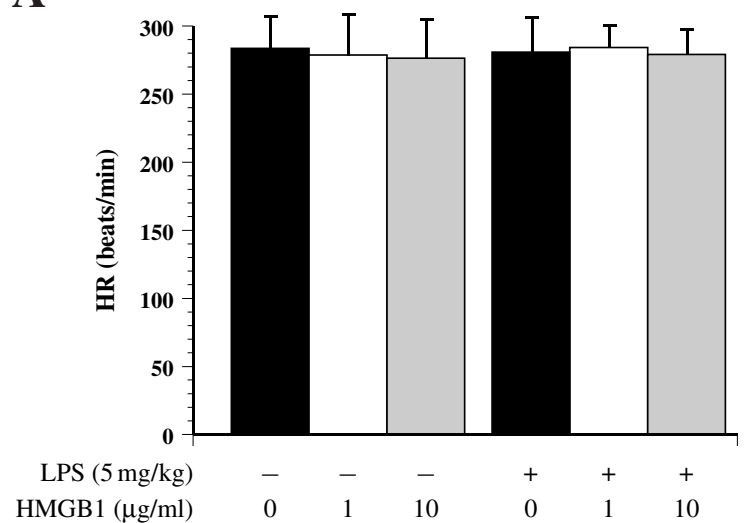

B

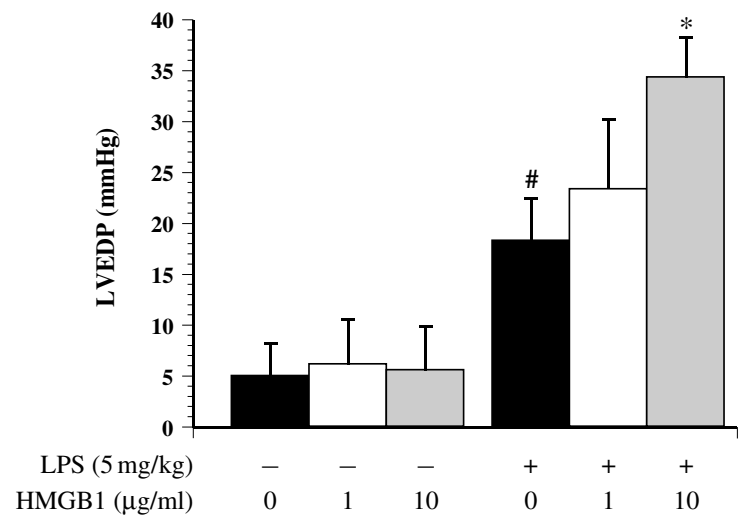

D

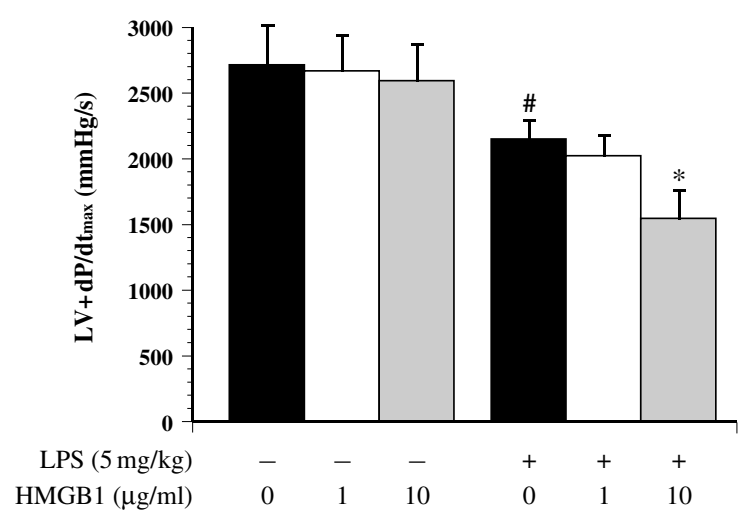

$\mathbf{E}$

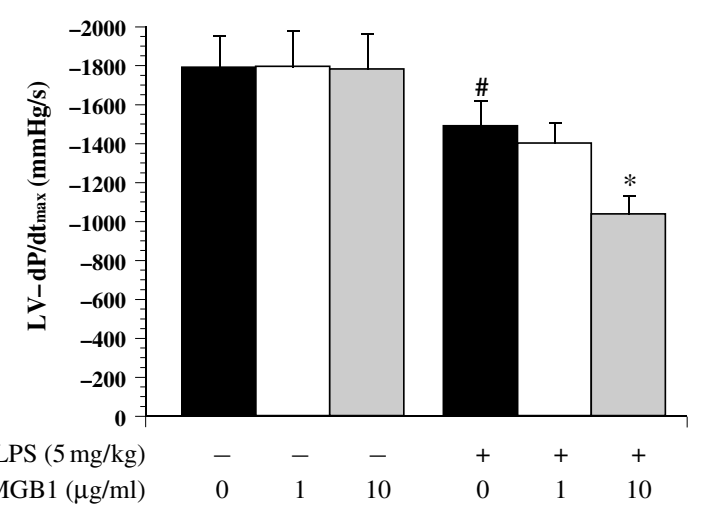

C

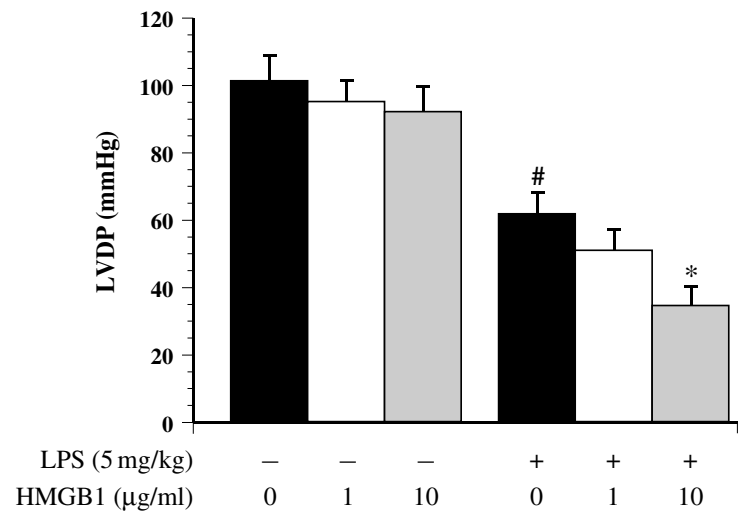

Fig 4. Effects of LPS and HMGB1 treatment on heart function in rats from a LPS-induced sepsis model. (A) Heart rate, (B) LVEDP, (C) LVDP, (D) $+\mathrm{dP} / \mathrm{dtmax},(\mathrm{E})-\mathrm{dP} / \mathrm{dtmin}$. Data are mean \pm SEM from 6 animals in the control and LPS-treated groups. *p<0.05 vs LPS (+) HMGB1 (0). \#p<0.05 vs LPS (-) HMGB1 (0). LVDP, left ventricular developed pressure; LVEDP, left ventricular end-diastolic pressure. See Figs 1,2 for other abbreviations.

dtmax or LV-dP/dtmin (data not shown). Hearts perfused with HMGB1 at concentrations of 1 or $10 \mu \mathrm{g} / \mathrm{ml}$, however, showed significantly increased LVEDP in the LPS group, compared with the control group (Fig 4B). In contrast, hearts perfused with HMGB1 at concentrations of 1 or $10 \mu \mathrm{g} / \mathrm{ml}$ showed markedly decreased LVDP (Fig 4C), $\mathrm{LV}+\mathrm{dP} / \mathrm{dtmax}$ (Fig 4D), and LV-dP/dtmin (Fig 4E), relative to the control group. These observed effects on cardiac function occurred in an HMGB1 dose-dependent manner. We next examined the effect of $10 \mu \mathrm{g} / \mathrm{ml} \mathrm{HMGB1}$ on hemodynamic parameters over time. All of the previously described effects were apparent within $1 \mathrm{~min}$ after exposure and remained relatively stable throughout the 10 -min period of exposure (Figs 5A-D). After $10 \mathrm{~min}$, HMGB1 was washed from the perfused hearts and all parameters immediately returned to baseline.

\section{Discussion}

Our results suggest that HMGB1 played an important role in causing decreased myocardial activity in a rat model of septic shock. Within $12 \mathrm{~h}$ of administration, LPS caused a significant increase in the level of HMGB1 in serum and cardiac tissue. In addition, recombinant HMGB1 repro- 
A

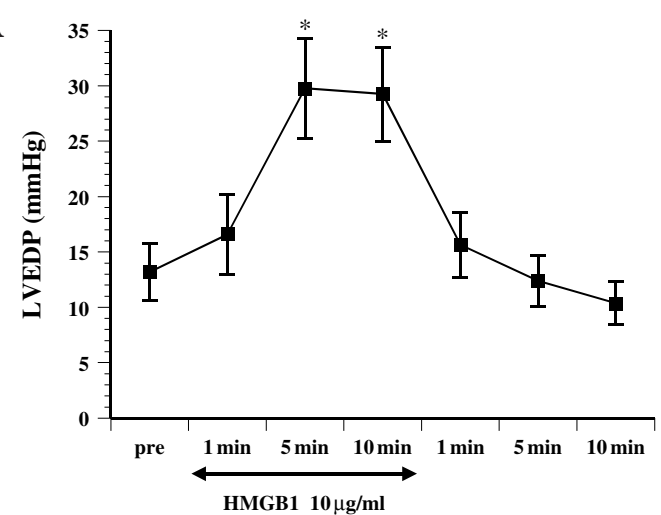

B

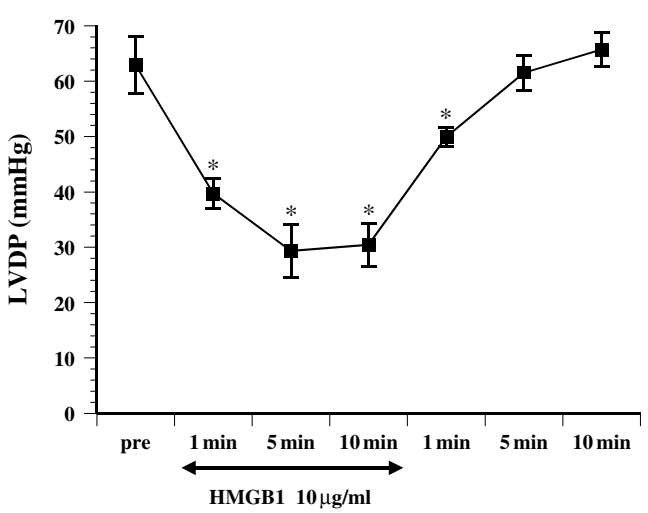

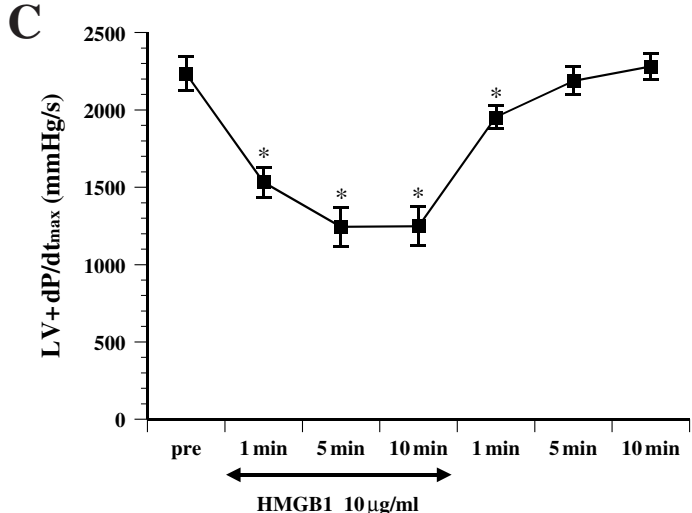

D

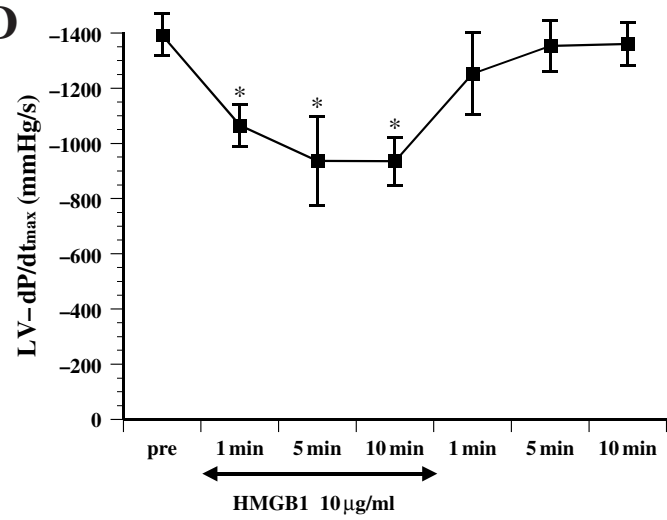

Fig 5. Time course analysis of hemodynamic parameters after exposure to 19u g/ml of HMGB1. (A) LVEDP; (B) LVDP; (C) $+\mathrm{dP} / \mathrm{dt} \max ;(\mathrm{D})-\mathrm{dP} / \mathrm{dtmin}$. Data are mean \pm SEM from 6 animals in the LPS group. ${ }^{*} \mathrm{p}<0.05$ vs pretreatment with HMGB1. See Figs 1,2,4 for abbreviations.

duced the effects of LPS-induced septic shock on rat cardiac function. This study is the first to demonstrate that HMGB1 serves as a late mediator of endotoxin-induced cardiac dysfunction in vivo. Taken together, our findings indicate that HMGB1 must be locally present in cardiac tissue within $12 \mathrm{~h}$ after LPS challenge to cause cardiac dysfunction.

This result is critical because cardiac dysfunction during sepsis is associated with poor outcome in both humans and animals? ${ }^{3-5}$ Several previous studies have shown that sepsisassociated cardiac dysfunction is primarily related to circulating myocardial depressant factors, including tumor necrosis factor (TNF) a ${ }^{15}$ However, because TNFa is a sentinel, rapid-response cytokine and is removed from the circulation several days before the resolution of myocardial dysfunction, it is clear that there are other mediators involved. HMGB1, widely known as a nuclear structural protein, has been identified as a late mediator of delayed endotoxin lethality 16 and is an excellent candidate protein to exert these effects. In humans, patients with sepsis or systemic inflammatory response syndrome have significantly elevated plasma levels of HMGB1.6

HMGB1 is a nuclear protein that acts as a DNA chaperone in normal cells and promotes DNA-protein interactions. ${ }^{17}$ It has been shown to play an important role in various types of inflammation and is thought to contribute to the pathology and mortality of sepsis, presumably as a late phase inflammatory mediator ${ }^{18}$ In addition, HMGB1 is an important mediator of cell death, and its expression occurs at a relatively late phase following injury! 16

In this study, we found that HMGB 1 expression was elevated in cardiac tissue and serum $12 \mathrm{~h}$ after LPS adminis- tration in a rat septic shock model. In this model, the hearts from LPS-treated animals showed increased LVEDP and decreased LVDP, LV+dP/dtmax, and absolute value of $-\mathrm{dP} / \mathrm{dtmin}$, compared with the hearts from untreated rats.

We also examined the direct effect of HMGB1 on cardiac function following endotoxin exposure by perfusing recombinant HMGB1 into the hearts from LPS-treated animals. This treatment did not affect HR, but it did augment the increase in LVEDP normally seen in LPS-treated animals, as well as further augment the decrease in LVDP, $\mathrm{LV}+\mathrm{dP} / \mathrm{dtmax}$, and the absolute value of $-\mathrm{dP} / \mathrm{dtmin}$ in a dosedependent manner. Recent studies reported that exogenous HMGB1 improved cardiac function and myocyte regeneration after infarction; ${ }^{19,20}$ however, in our model of septic shock, HMGB1 had a negative inotropic effect. This is the first report of exogenous HMGB1 having an inhibitory effect on cardiac function in a septic shock model, which is different from other reports. The mechanism by which HMGB1 inhibits cardiac function is unknown, and thus requires further study.

In summary, our results suggest that HMGB1 plays a critical role in the myocardial dysfunction that follows endotoxin-induced septic shock. Our study examined only the effects of recombinant HMGB1 in the endotoxin-treated rat heart. Further extension of these studies may confirm that HMGB1 could be a new therapeutic target for ameliorating myocardial dysfunction in septic shock.

\section{References}

1. Krishnagopalan S, Kumar A, Parrillo JE, Kumar A. Myocardial dys- 
function in the patient with sepsis. Curr Opin Crit Care 2002; 5: 376-388.

2. Reilly JM, Cunnion RE, Burch-Whitman C, Parker MM, Shelhamer $\mathrm{JH}$, Parrillo JE. A circulating myocardial depressant substance is associated with cardiac dysfunction and peripheral hypoperfusion (lactic acidemia) in patients with septic shock. Chest 1989; 95: $1072-1080$

3. Ognibene FP, Parker MM, Natanson C, Shelhamer JH, Parrillo JE. Depressed left ventricular performance: Response to volume infusion in patients with sepsis and septic shock. Chest 1988; 93: 903-910.

4. Parker MM, Shelhamer JH, Bacharach SL, Green MV, Natanson C, Frederick TM, et al. Profound but reversible myocardial depression in patients with septic shock. Ann Intern Med 1984; 100: 483-490.

5. Natanson C, Danner RL, Elin RJ, Hosseini JM, Peart KW, Banks $\mathrm{SM}$, et al. Role of endotoxemia in cardiovascular dysfunction and mortality: Escherichia coli and Staphylococcus aureus challenges in a canine model of human septic shock. J Clin Invest 1989; 83: 243 251.

6. Bustin M. Regulation of DNA-dependent activities by the functional motifs of the high-mobility-group chromosomal proteins. Mol Cell Biol 1999; 19: 5237-5246.

7. Fiuza C, Bustin M, Talwar S, Tropea M, Gerstenberger E, Shelhamer $\mathrm{JH}$, et al. Inflammation-promoting activity of HMGB1 on human microvascular endothelial cells. Blood 2003; 101: 2652-2660.

8. Park JS, Gamboni-Robertson F, He Q, Svetkauskaite D, Kim JY, Strassheim D, et al. High mobility group box 1 protein (HMGB1) interacts with multiple Toll like receptors. Am J Physiol Cell Physiol 2006; 290: 917-924.

9. Kokkola R, Andersson A, Mullins G, Ostberg T, Treutiger CJ, Arnold B, et al. RAGE is the major receptor for the proinflammatory activity of HMGB1 in rodent macrophages. Scand J Immunol 2005; 61: $1-9$.

10. Cohen J. The immunopathogenesis of sepsis. Nature 2002; 420: $885-891$

11. Hagiwara S, Iwasaka H, Matumoto S, Noguchi T. Nafamostat mesi- late inhibits high-mobility group box 1 by lipopolysaccharide stimulation in murine macrophage RAW 264.7. Shock 2007; 27: 429-435.

12. Meng X, Ao L, Brown JM, Fullerton DA, Banerjee A, Harken AH. Nitric oxide synthase is not involved in cardiac contractile dysfunction in a rat model of endotoxemia without shock. Shock 1997; 7: $111-118$.

13. Meng X, Brown JM, Ao L, Banerjee A, Harken AH. Norepinephrine induces cardiac heat shock protein 70 and delayed cardioprotection in the rat through alpha 1 adrenoceptors. Cardiovasc Res 1996; 32: $374-383$.

14. Meng X, Brown JM, Ao L, Nordeen SK, Franklin W, Harken AH, et al. Endotoxin induces cardiac HSP70 and resistance to endotoxemic myocardial depression in rats. Am J Physiol 1996; 271: C1316C1324.

15. Kumar A, Thota V, Dee L, Olson J, Uretz E, Parrillo JE. Tumor necrosis factora and interleukin $\mathbb{B}$ are responsible for in vitro myocardial cell depression induced by human septic shock serum. J Exp Med 1996; 183: 949-958.

16. Wang H, Yang H, Czura CJ, Sama AE, Tracey KJ. HMGB1 as a late mediator of lethal systemic inflammation. Am J Respir Crit Care Med 2001; 164: 1768-1773.

17. Bonaldi T, Langst G, Strohner R, Becker PB, Bianchi ME. The DNA chaperone HMGB1 facilitates ACF/CHRAC-dependent nucleosome sliding. EMBO J 2002; 21: 6865-6873.

18. Ueno H, Matsuda T, Hashimoto S, Amaya F, Kitamura Y, Tanaka $\mathrm{M}$, et al. Contributions of high mobility group box protein in experimental and clinical acute lung injury. Am J Respir Crit Care Med 2004; 170: 1310-1316.

19. Chavakis E, Hain A, Vinci M, Carmona G, Bianchi ME, Vajkoczy P, et al. High-mobility group box 1 activates integrin-dependent homing of endothelial progenitor cells. Circ Res 2007; 100: 204-212.

20. Limana F, Germani A, Zacheo A, Kajstura J, Di Carlo A, Borsellino $\mathrm{G}$, et al. Exogenous high-mobility group box 1 protein induces myocardial regeneration after infarction via enhanced cardiac C-kit+ cell proliferation and differentiation. Circ Res 2005; 97: e73-e83. 